\title{
Computational studies for comparison between BRB dampers and SERB new romanian dampers performance in damping system of high buildings
}

\author{
Ionescu Adriana ${ }^{1, a}$ \\ ${ }^{1}$ University of Craiova, Faculty of Mechanics, Romania \\ aadita_i@yahoo.com
}

Keywords: BRB dampers, SERB C-194 dampers, earthquake, seismic dampers, hysteresis.

\begin{abstract}
This paper presents a computational study for comparison of the behavior of a ten stories building equipped with two type of damping system: Buckling Restrained Braces (BRB dampers) and SERB new romanian dampers, during romanian earthquakes, according to romanian codes for seismic analysis. This study was computationally finalized using a software program made by the authors which permits time-history dynamic analysis of buildings equipped with different damping devices with different hysteresis such as: Maxwell, Kelvin-Voigt, Zener, Bouc-Wen, Taylor. The study will compare the drifts and the forces applied to the structure by the dampers. The SERB C194 dampers are a cheaper way to protect the building during earthquake and restrict the drifts similarly with BRB dampers.
\end{abstract}

\section{Introduction}

The most used devices for dissipating the seismic energy and protecting the buildings during earthquakes are the dampers positioned at the building supra-structure.

The damping system with SERB new romanian dampers has as advantage the costs which is very low. The damping forces for SERB dampers are increasing with the displacements.

Buckling Restrained Brace (BRB) devices are used to increase the resistance of frame structures by providing energy dissipation and introducing nonlinear behaviour.

The BRB has three components: a slender steel core, where the energy can be dissipated; a concrete casing in a steel hollow section, which supports the core laterally under compression, and an air gap separating the two parts from each other.

In BRB case, the advantageous dissipative properties of the steel material are used by limiting the amplitude of buckling of compressed bracing element, and resulting in braces capable of significant energy dissipation.

\section{Theoretical background}

The program software which was made by the author in DELPHI programming language for studying the behavior of the buildings with different damping systems subjected to earthquakes is based on the equation:

$$
M \cdot \ddot{x}+C \cdot \dot{x}+K \cdot x=F .
$$

where: $\mathrm{M}$ - the mass matrix

$\mathrm{C}$ - the damping matrix

$\mathrm{K}$ - the stiffness matrix

$\mathrm{F}$ - the force vector

$x$ - the displacement vector

In order to express the hysteresis curves of BRB dampers and SERB dampers in mathematical models we have used the Bouc-Wen model of hysteresis. 
The relationship beetwen the damping forces and the displacements for the Bouc-Wen model is described by the equation:

$$
\frac{\mathrm{d} z}{A-|z|^{n}\left[\beta+\gamma \operatorname{sgn}\left(\xi^{\prime} z\right)\right]}=\mathrm{d} \xi
$$

where: $A, \beta, \gamma, n$ are the parameters which controls the magnitude and shape of hysteresis curve, $z(\xi)$.

These parameters are determined after the experimental testing of BRB dampers and SERB dampers by fitting the theoretical hysteresis curve with the hysteresis curve determined by experiments.

\section{Computational studies}

The software we have created and use is GenEcAm software, and he can simulate buildings with maximum 20 stories equipped with different types of dampers with five types of non-linear hysteresis: Maxwell, Kelvin-Voigt, Zener, Viscous dampers (Taylor) and Bouc-Wen (BRB dampers and SERB dampers).

The analysis made by the program is a time-history dynamic analyses which needs an accelerogram for input.

For comparison we have analyzed a ten stories building in three different cases:

- case 1: without damping system;

- case 2: with two SERB dampers (Bouc-Wen hysteresis) on each story with the parameters: $A=0.02, \beta=-6.5, \gamma=4, F_{d}=1000 \mathrm{kN}, y_{d}=0.008 \mathrm{~m}$;

- case 3: with two BRB dampers (Bouc-Wen hysteresis) on each story, with the parameters: $A=5, \beta=1, \gamma=4, F_{d}=1000 \mathrm{kN}, y_{d}=0.008 \mathrm{~m}$.

$F_{d}$ and $y_{d}$ are the maximal values for the forces and the displacements within the BRB dampers used.

The accelerogram used is an artificial accelerogram with $\mathrm{PGA}=0.3 \mathrm{~g}$ and $\mathrm{T}_{\mathrm{c}}=1.6 \mathrm{~s}$.

The dampers in each case are positioned in chevron configuration.

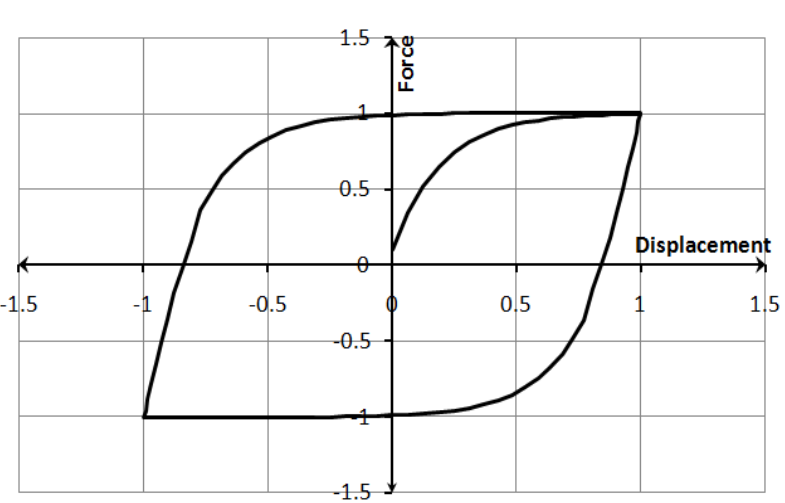

a)

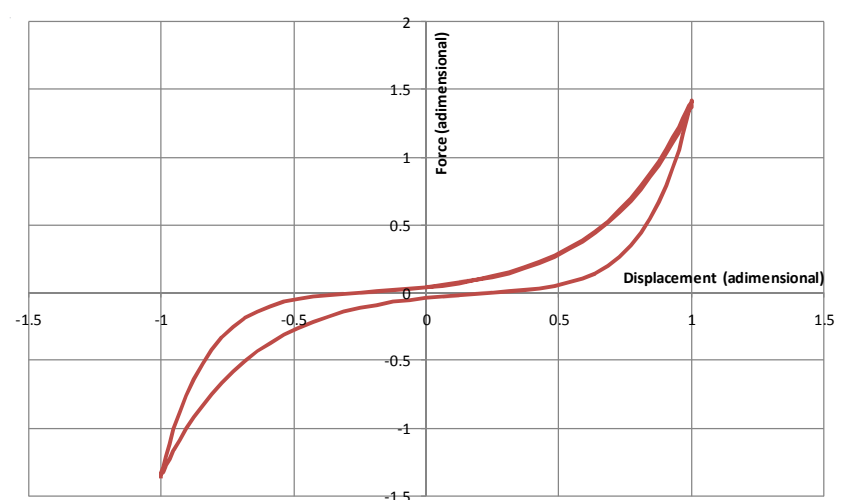

b)

Fig. 1 Bouc-Wen model of hysteresis for

a) BRB dampers and b) SERB dampers

\section{Comparison results}

The results obtained with our GenEcAm software for all three cases of analyses are displacements, drifts and damping forces. The software permits to animate the building during earthquake and taking snapshots for analysis and comparison. 
As we can see in Fig. 2-4, the maximal drifts of building equipped with BRB dampers (case 2) and SERB dampers (case 3) are around $6 \mathrm{~mm}$. For the building without dampers, the maximal drift is $8.2 \mathrm{~mm}$. The effect of using the damping system in case 2 and 3 is the diminishing of drifts with $25 \%$.
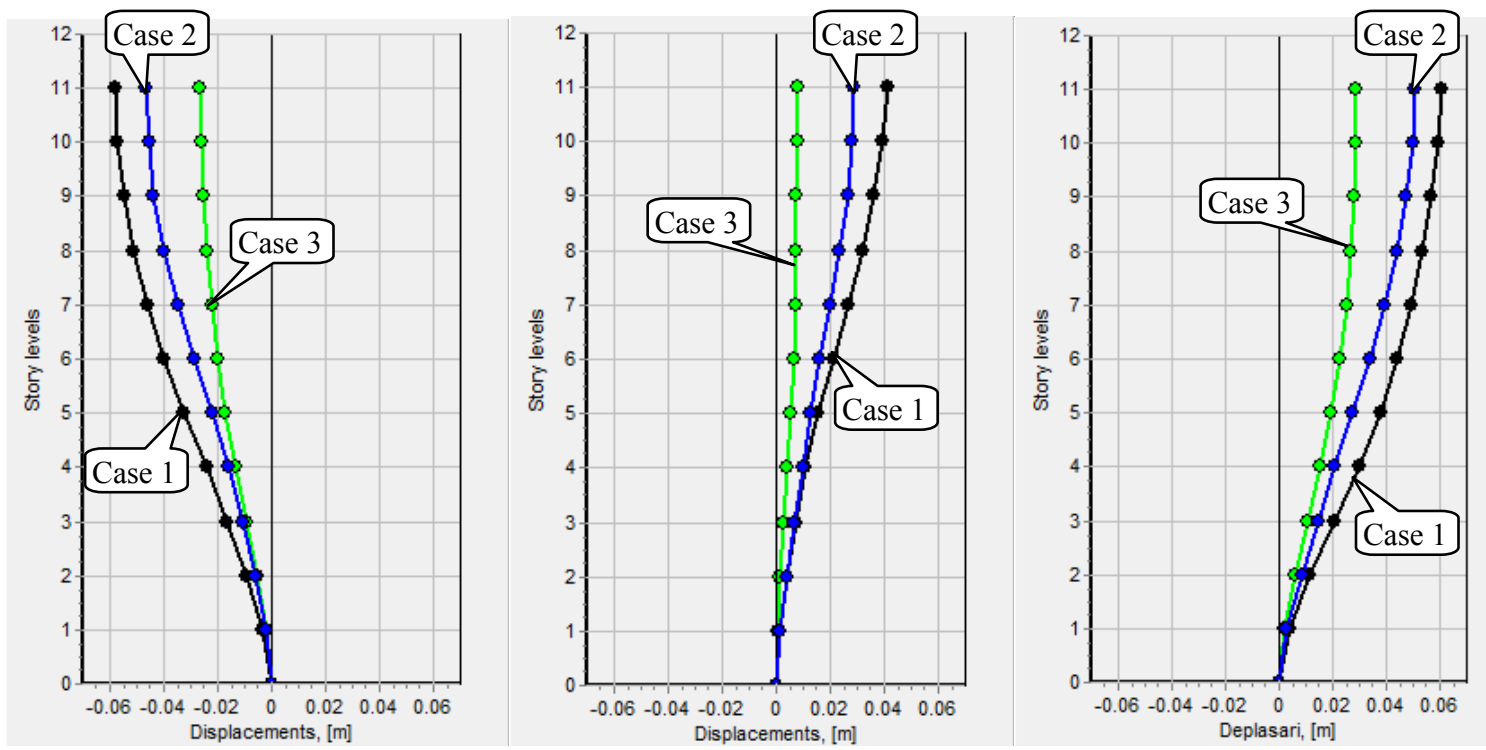

Fig. 2 Snapshots for displacements during earthquake at $2.7 \mathrm{~s}, 5.2 \mathrm{~s}$ and $10.1 \mathrm{~s}$


Fig. 3 Snapshots for drifts during earthquake at $2.7 \mathrm{~s}, 5.2 \mathrm{~s}$ and $10.1 \mathrm{~s}$


Fig. 4 Variation of drifts at story three during earthquake

As we see the drifts in case 2 and 3 are similar and with $25 \%$ smaller than case 1. 
In order to compare the performances of the damping systems with BRB dampers and with SERB dampers it is useful to compare the damping forces which are transmitted to the building structure.

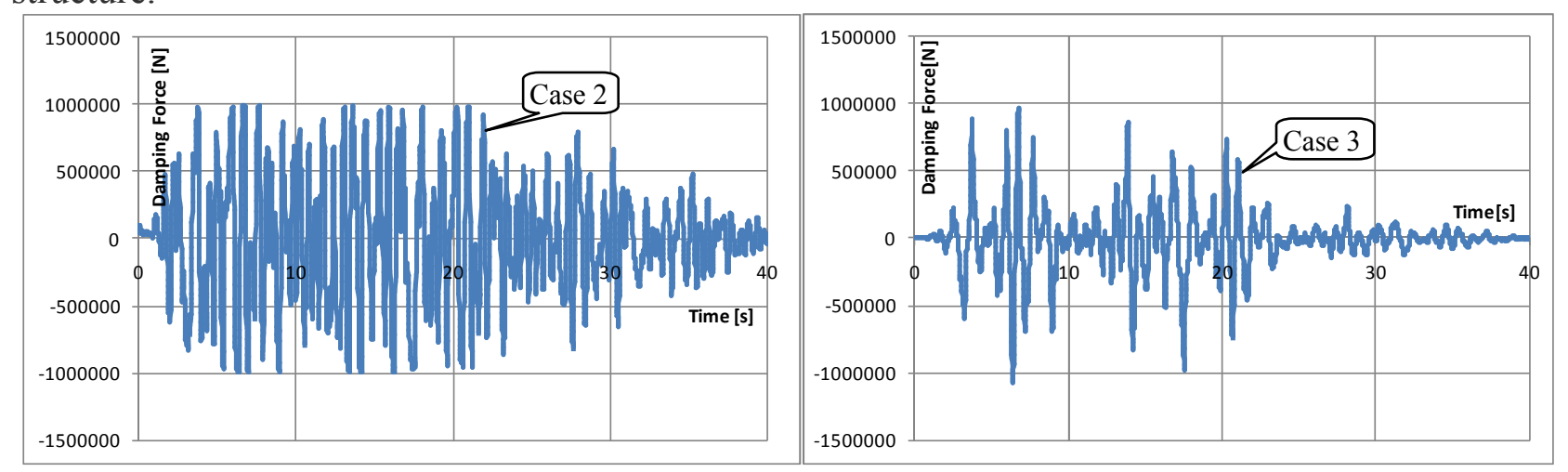

Fig. 5 Variation of damping forces at story three during earthquake

The maximal values of the damping forces which appears within dampers in both damping systems are the same, both are around $1000 \mathrm{KN}$, but the variation of these forces are very different.

\section{Conclusions}

By analyzing the figures presented we can conclude that:

- the forces for both damping systems have the same maximal values;

- $\quad$ using BRB dampers, the forces transmitted to the building structure determine the appearing of a more active control than when we use SERB dampers

- the maximal drifts for both damping systems are diminishing in both cases with $25 \%$;

- the drifts for upper stories are relatively bigger when we use SERB dampers than when we use BRB dampers, but they not exceed $6 \mathrm{~mm}$.

The final conclusion is that the efficiency for protecting the buildings during earthquakes is similar for both damping systems but the control determined by BRB dampers is more intense. We can observe that the building structure is more subjected to damping forces in the case of BRB dampers than by using SERB dampers. The seismic energy dissipation is bigger in the case of damping system with BRB dampers than when we use SERB dampers.

\section{References}

[1] A. Ionescu, M. Calbureanu, M. Negru - Static and Dynamic Simulation in the Seismic Behavior of a Building Structure using ANSYS Program, International Journal of Mechanics, NAUN Journal 2013, vol. 7, pag. 210-217, ISSN: 1998-4448.

[2] A. Ionescu, M. Negru, C. Burada, Influence of non-linear properties of fluid viscoelastic properties on seismic damping properties of a ten stories building using ANSYS program, Journal Advanced Concepts in Mechanical Engineering, ACME 2014, Trans Tech Publication, Switzerland.

[3] A. Ionescu, M. Negru, C. Burada, Optimal configuration of fluid viscoelastic seismic dampers on a ten stories building using Finite Elements Method, Journal - Advanced Concepts in Mechanical Engineering, ACME 2014, Trans Tech Publication, Switzerland.

[4] A. Ionescu, M. Calbureanu, M. Negru, The comparison of the results in seismic behavior of a building using static and dynamic methods in ANSYS program WSEAS International Conference, Vouliagmeni, Athens, Greece, may 14-16, 2013.

[5] A. Ionescu, C. Burada, M. Calbureanu, M. Negru, F.E.M. studies concerning new devices for seismic damping of buildings subjected to romanian Vrancea earthquakes, $3^{\text {rd }}$ International Conference WSEAS, ABIFA'14, Brasov, Romania, june 26-28, 2014. 